\title{
Spasm of the Near Reflex: Clinical Appearance
} Yakın Refleks Spazmı: Klinik Görünüm

(1) Ezgi Yakupoğlu1 , (1) Yusuf Emre Doğan², (1) Nihan Parasız Yükselen1, () Pelin Doğan Ak1, (1) Eren Gözke1 1 Istanbul Fatih Sultan Mehmet Training and Research Hospital, Clinic of Neurology, Istanbul, Turkey 2Manisa Demirci State Hospital, Clinic of Ophthalmology, Manisa, Turkey

Keywords: Spasm of the near reflex, accommodative spasm, convergence, myosis

Anahtar Kelimeler: Yakın refleks spazmı, akomodasyon spazm1, konerverjans, miyozis

\section{Dear Editor,}

An 18-year-old female patient was admitted to our clinic with sudden-onset horizontal binocular diplopia, marked headache on the left eyebrow, and limited abduction of the left eye that started one day ago. The patient noted that she had had similar symptoms that resolved spontaneously before, but that this time it was more severe. The patient had no history of febrile illness; trauma; regular medication use; neurologic, psychiatric or other systemic disease; and ocular surgery. A neurologic examination revealed intact visual acuity in both eyes and horizontal diplopia. In the primary position, there was left convergent strabismus (Figure 1). On light reflex examination, the left pupil was meiotic. Bilateral pathology was not observed in extraocular muscles (Figures 2A, 2B). The examination performed by the ophthalmology clinic revealed no pathology in the anterior and posterior segment of the eye, and

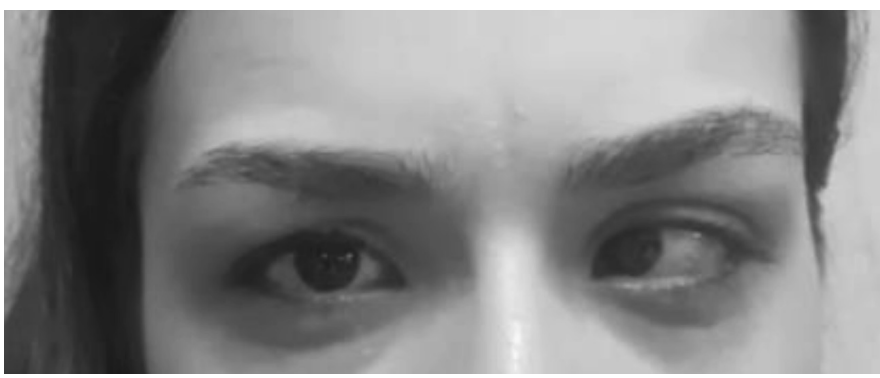

Figure 1. In the primary position, there was left convergent strabismus.
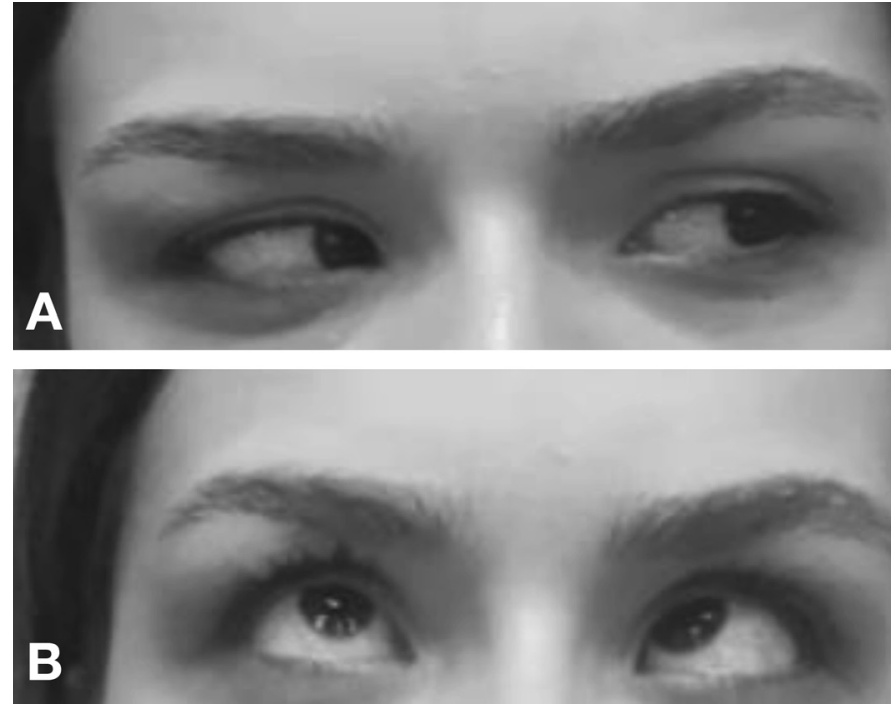

Figure 2. A, B) There was no pathology in the extraocular muscle movements.

the optic disc was normal. Visual field examination with visual achromatic perimetry was normal. No pathology was found in the remaining neurologic or ophthalmologic examinations.

Cranial computed tomography (CT), CT angiography, and magnetic resonance imaging showed no pathology. Thyroid

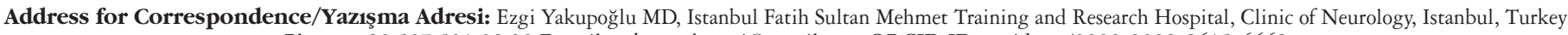
Phone: +90 5075310230 E-mail: yakupogluezgi@gmail.com ORCID ID: orcid.org/0000-0002-8615-6668

Received/Geliş Tarihi: 16.05 .2018 Accepted/Kabul Tarihi: 23.10 .2018

${ }^{\circ}$ Copyright 2019 by Turkish Neurological Society

Turkish Journal of Neurology published by Galenos Publishing House. 
function tests, liver and kidney function tests, repetitive nerve stimulation of the extraocular muscles, and lumbar puncture were found to be normal.

Functional spasm of the near reflex was considered because there was no organic pathology. Signs and symptoms improved significantly following cyclopentolate eye drop administration (Figure 3). The patient was given simultaneous psychological support and the patient's symptoms disappeared completely in the sixth month of the follow-up.

Functional near reflex spasm is rare, but it is a chronic clinical condition (1). It should be considered in the diagnosis when episodic diplopia is accompanied by myosis and disconjugate gaze (2). After excluding organic causes, functional reasons should be considered. Refractive errors should be corrected (3). Cycloplegic agents can temporarily relieve symptoms $(4,5)$. Functional cases need psychological support and it should be noted that there is a possibility of recurrence in these cases (5).

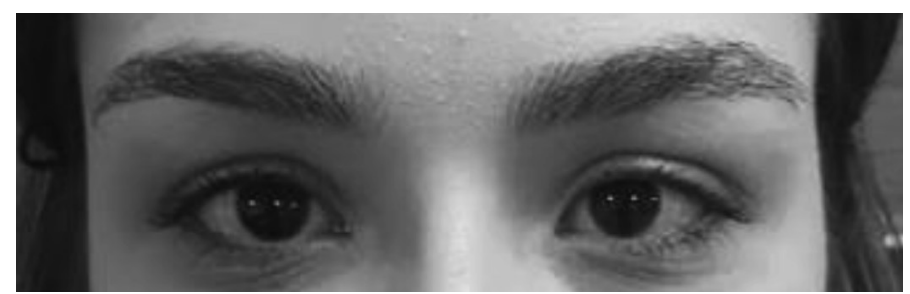

Figure 3. Signs and symptoms improved significantly following cyclopentolate eye drop administration.

\section{Ethics}

Informed Consent: Consent form was filled out by a participant.

Peer-review: Internally peer-reviewed.

Authorship Contributions

Surgical and Medical Practices: E.Y., Y.E.D., Concept: E.Y., Design: E.Y., Y.E.D., Data Collection or Processing: E.Y., Y.E.D., Analysis or Interpretation: N.P.Y., P.D.A., Literature Search: E.Y., N.P.Y., P.D.A., Writing: E.Y.

Conflict of Interest: No conflict of interest was declared by the authors.

Financial Disclosure: The authors declared that this study received no financial support.

\section{References}

1. Rhatigan M, Byrne C, Logan P. Spasm of the near reflex: A case report. Am J Ophthalmol Case Rep 2017;6:35-37.

2. Goldstein JH, Schneekloth BB. Spasm of the near reflex: a spectrum of anomalies. Surv Ophthalmol 1996;40:269-278.

3. Savin LH. Functional spasm of accommodation. Br J Ophthalmol 1959;43:38.

4. Fekete R, Baizabal-Carvallo JF, Ha AD, Davidson A, Jankovic J. Convergence spasm in conversion disorders: Prevalence in psychogenic and other movement disorders compared with controls. J Neurol Neurosurg Psychiatry 2012;83:202-204.

5. Cogan DG, Freese CG Jr. Spasm of the near reflex. AMA Arch Ophthalmol $1955 ; 54: 752-759$. 